\title{
Serum Adenosine Deaminase: A Novel Biomarker Tool for the Diagnosis of Tuberculosis
}

\author{
Raju Pandey ${ }^{1}$, Dipesh Tamrakar ${ }^{1}$, Suresh Jaiswal ${ }^{1}$, Anup Sharma ${ }^{1}$, Sujan Koju ${ }^{1}$, \\ Surya Ram Duwal ${ }^{1}$, Ishor Sharma ${ }^{2}$, Rajesh P. Jayaswal ${ }^{3}$ and Pranay P. Pankaj ${ }^{4}$
}

${ }^{1}$ Department of Medical Lab Science, Pokhara University, Kaski, Nepal, India.

${ }^{2}$ Department of Public Health, Pokhara University, Kaski, Nepal, India.

${ }^{3}$ Department of Paramedical Sciences, Lovely Professional University, Punjab, India

${ }^{4}$ Department of Zoology, Nagaland University, Lumami, Nagaland - 798627, India.

http://dx.doi.org/10.13005/bbra/2068

(Received: 10 January 2016; accepted: 15 February 2016)

\begin{abstract}
Tuberculosis is a major health issues worldwide. Every year more than 9 million new cases are reported worldwide with death rate of around 2 million each year. Rapid and accurate diagnosis of tuberculosis in population is most supportive in proper medication and early recovery. The golden standard method for diagnosis of tuberculosis in patient is formerly culture method which is time consuming and cumbersome. Various other techniques used in the diagnosis of tuberculosis have poor sensitivity and specificity however serum adenosine deaminase (ADA) has emerged as a potent biochemical marker that can be used as tool for the diagnosis of tuberculosis for rapid, easy and better result. Increased level of ADA in blood generally indicates the presence of tuberculosis. In the present study, the serum ADA level was examined in 75 healthy control and 75 tuberculosis patients with positive sputum smear for acid fast bacilli (AFB), having clinical symptoms were diagnosed for pulmonary tuberculosis and radiological impression for extra pulmonary tuberculosis. The selection of cases and control were based on the inclusion and exclusion criteria. Samples were collected at the outpatient department of National Tuberculosis Centre, Nepal after asking simple questionnaires. Modified Guisti and Galanti method was adopted for estimation of serum ADA from pooled and processed blood samples. There was significant difference $(p<0.001)$ in mean rank of level of serum ADA among the TB cases to controls. The P-TB had the highest mean rank (116.52) followed by EP-TB (99.48) and control had significantly less mean rank (40.16). At the cut-off point of $25 \mathrm{U} / \mathrm{L}$; sensitivity, specificity, positive predictive value and negative predictive value were $90.7 \%, 100 \%, 90.66 \%$ and $100 \%$ respectively. It can be concluded from data that there were insignificant difference in mean rank among sex wise distribution with $p=0.037$ and sputum grading wise distribution with $\mathrm{p}=0.142$.
\end{abstract}

Key words: Tuberculosis, Adenosine deaminase,

Pulmonary tuberculosis, Acid Fast Bacilli, Mycobacterium.

Tuberculosis is a chronic granulomatous infectious disease commonly known with TB which is caused by the bacillus $M$. tuberculosis. It typically affects the lungs usually called pulmonary TB but can affect other sites as well including various organs, also called as extra-

\footnotetext{
* To whom all correspondence should be addressed. Mob.: +91-9771162090;

E-mail: pranaypunj@gmail.com
}

pulmonary TB. People who are infected with pulmonary TB expel bacteriain the air by coughing and the disease is spread to healthy person. TB remains a major global health problem in the world. It causes ill-health among millions of people each year and ranks as the second leading cause of death from an infectious disease worldwide after HIV/ AIDS.

Adenosine deaminase (ADA, adenosine aminohydrolase, EC 3.5.4.4), an enzyme involved 
in purine metabolism, catalyses the hydrolytic cleavage of adenosine and 2'deoxyadenosine, irreversible converting them into inosine and 2'deoxyinosine respectively. ADA activity increases during cellular activation for energy demand to detoxify the toxic metabolites. It plays an important role in lymphocyte and monocyte maturation and activity. ADA is essential for proliferation and differentiation of lymphoid cells, especially $\mathrm{T}$ cells, and helps in the maturation of monocytes to macrophages. ADA seems to be an index for cellular immunity. Increased serum level of ADA has been reported in several diseases characterized by an enhanced cell mediated immune (CMI) response, such as typhoid fever, bacterial pneumonia, infectious mononucleosis and tuberculosis.

Recent studies showed extensive delay in TB diagnosis ${ }^{1-2}$. There are different diagnostic methods but they have some drawbacks. To culture TB bacterium is the golden standard for TB diagnosis usually takes 8 weeks. The polymerase chain reaction (PCR) test for TB diagnosis is expensive and it requires skilled personnel and lot of sophisticated equipment. Therefore, in recent years, there has been a great demand for finding new microbiological, genetic, immunological and biomedical diagnostic methods to diagnose TB quickly and accurately. ADA is an enzyme which contributes in purine metabolism. Measuring of adenosine deaminase (ADA) activity is a biomedical method used in diagnosis of $\mathrm{TB}^{3-6}$. The previous studies have proved its value in TB diagnosis, even for assessing TB effusions in which activity of this enzyme increases in the infected patients ${ }^{7}$.In some studies, the level of ADA in body fluids and serum was used for diagnosis of TB and it was monitored during TB treatment ${ }^{8}$. Initial studies used effusion fluids and a very limited number of studies used patients' serum ${ }^{9}$. Since, it is not always possible to access effusion liquids everywhere in pulmonary and extra pulmonary TB; therefore, it would be helpful to take advantage of serum levels. The goal of this study was to assess the diagnostic value and cut off point of serum ADA levels in TB patients. This test may be ordered as one of several tests to help rule in or rule out $\mathrm{TB}$. The objectives of the present studies were to determine the level of serum ADA in tuberculosis cases of different population, cut off level for Serum ADA in diagnosis of TB and sensitivity and specificity determination of serum $\mathrm{ADA}$ in the diagnosis of tuberculosis

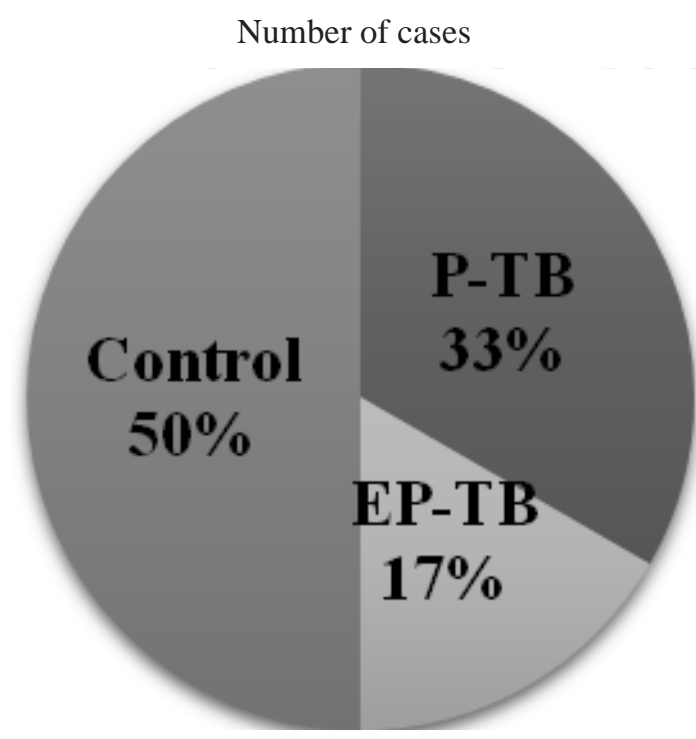

Fig. 1. Total number of cases

\section{MATERIALSAND METHODS}

A cross-sectional case control study was conducted among the patients visiting National Tuberculosis Centre (NTC), Bhaktapur, Nepal. NTC is the major centre for the study of tuberculosis in Nepal where every day more than 50 patients with tuberculosis visit for treatment. Since our study was concerned with tuberculosis, we could easily get the cases of tuberculosis of our concern. The patients attending NTC are from almost all parts of Nepal and we could include the cases from various parts of Nepal and of different ages and sex. We performed sample collection in the Out Patient Department (OPD) of NTC from cases with verbal consent. The separated serum samples were stored at -4 to $0^{\circ} \mathrm{C}$ and were processed in the biochemistry laboratory of Dhulikhel Hospital, Nepal. The ethical consent was taken from the authority of National Tuberculosis Centre (NTC) for sample collection and from Department of Biochemistry, Dhulikhel Hospital for sample processing.

Quantitative method: Determination of serum ADA from the cases and control was based on the principle of Guisti \& Galanti (1974) methods of enzymatic analyses. ADA-MTB diagnostic kit from Microxpress a division of Tulip diagnostics 
(P) Ltd., Goa, India was used for the determination of ADA activity in serum,

\section{RESULTS}

Out of total 150 cases, 75 (50\%) were healthy control group and 75 (50\%) were TB cases. Among TB case, there were 50 (33\%) cases of Pulmonary TB and 25 (17\%) cases of Extra Pulmonary TB.

The Mean age of study groups were 34.20 yrs. of Pulmonary TB cases followed by 30.12 yrs. of Extra Pulmonary TB and 26.13 yrs. of healthy control.

Table 2 and demonstrates that the Mean Rank of Serum ADA level were shown highest 116.52 U/L in Pulmonary TB cases followed by 99.48 U/L in Extra Pulmonary TB and lowest of 40.16 U/L in healthy control cases. The mean rank level of Serum ADA was shown to be statistically significant with p value of 0.001 .

The Mean Rank Serum ADA level in TB cases were shown higher $110.84 \mathrm{U} / \mathrm{L}$ than in Healthy control cases of $40.16 \mathrm{U} / \mathrm{L}$ with p value of 0.001 . The variation in Mean Rank was shown to be statistically significant.

The Mean Rank Serum ADA level was found higher in male of $41.82 \mathrm{U} / \mathrm{L}$ than in female of $30.81 \mathrm{U} / \mathrm{L}$ with p value of 0.037 . The variation of Mean Rank Serum ADA level among male and female was not found statistically significant.

Table 1. Age wise distribution of study population

\begin{tabular}{lll}
\hline $\begin{array}{l}\text { Study } \\
\text { Group }\end{array}$ & $\begin{array}{l}\text { No. of } \\
\text { Cases }\end{array}$ & $\begin{array}{l}\text { Age (years) } \\
\text { Mean } \pm \text { SD }\end{array}$ \\
\hline P-TB & 50 & $34.20 \pm 12.37$ \\
EP-TB & 25 & $30.12 \pm 8.93$ \\
Control & 75 & $26.13 \pm 5.75$ \\
\hline
\end{tabular}

Table 2. Mean Rank distribution of Serum ADA level among Study Groups

\begin{tabular}{lll}
\hline $\begin{array}{l}\text { Study } \\
\text { Group }\end{array}$ & $\begin{array}{l}\text { No. of } \\
\text { Cases }\end{array}$ & $\begin{array}{l}\text { ADA U/L } \\
\text { Mean Rank }\end{array}$ \\
\hline P-TB & 50 & $116.52 *$ \\
EP-TB & 25 & $99.48^{*}$ \\
Control & 75 & $40.16^{*}$ \\
\hline Kruskal-Wallis $=101.847$ & $* \mathrm{p}=0.001$
\end{tabular}

The highest level of Sensitivity, Specificity, Positive Predictive Value (PPV) and Negative Predictive Value (NPV) were seen at the Cut-off point of $25 \mathrm{U} / \mathrm{L}$ with $90.7 \%, 100 \%, 90.66 \%$ and $100 \%$ respectively. The highest sensitivity of

Table 3. Serum ADA U/L mean rank distribution among study group

\begin{tabular}{lll}
\hline $\begin{array}{l}\text { Study } \\
\text { Group }\end{array}$ & $\begin{array}{l}\text { No. of } \\
\text { Cases }\end{array}$ & $\begin{array}{l}\text { ADA U/L } \\
\text { Mean Rank }\end{array}$ \\
\hline TB & 75 & $\begin{array}{l}110.84^{*} \\
40.16^{*}\end{array}$ \\
\hline Control & 75 & $* p=0.001$
\end{tabular}

Table 4. Sex wise distribution of serum ADA U/L mean rank

\begin{tabular}{lc}
\hline Sex & ADA (U/L)Mean Rank \\
\hline Male & $41.82^{*}$ \\
Female & $30.81^{*}$ \\
\hline
\end{tabular}

Mann Whitney $=450.00 \quad{ }^{*} \mathrm{p}=0.037$

Table 5. Table showing sensitivity, specificity, PPV and NPV at different cut-off levels

\begin{tabular}{lcccc}
\hline $\begin{array}{l}\text { ADA (U/L) } \\
\text { Cut-off }\end{array}$ & $\begin{array}{c}\text { Sensitivity } \\
(\%)\end{array}$ & $\begin{array}{c}\text { Specificity } \\
(\%)\end{array}$ & $\begin{array}{c}\text { PPV } \\
(\%)\end{array}$ & $\begin{array}{c}\text { NPV } \\
(\%)\end{array}$ \\
\hline 21 & 93.3 & 93.3 & 93.33 & 93.33 \\
22 & 92.0 & 96.0 & 92.00 & 96.00 \\
23 & 90.7 & 97.3 & 90.66 & 96.00 \\
24 & 90.7 & 98.7 & 90.66 & 98.00 \\
25 & 90.7 & 100.00 & 90.66 & 100.00 \\
26 & 90.7 & 100.00 & 90.66 & 100.00 \\
27 & 85.3 & 100.00 & 85.33 & 100.00 \\
28 & 84.0 & 100.00 & 84.00 & 100.00 \\
29 & 81.3 & 100.00 & 81.33 & 100.00 \\
30 & 81.3 & 100.00 & 81.33 & 100.00 \\
\hline
\end{tabular}

Table 6. Serum ADA U/L MEAN rank distribution depending upon sputum AFB grading

\begin{tabular}{lcc}
\hline AFB Grading & No. of cases & ADA (U/L)Mean Rank \\
\hline $1+$ & 26 & $21.6^{*}$ \\
$2+$ & 7 & $29.14^{*}$ \\
$3+$ & 17 & $29.97^{*}$ \\
\hline
\end{tabular}

${ }^{*} \mathrm{p}=0.142$ 
Table 7. Mean Rank Serum ADA level distribution among sputum grading

\begin{tabular}{lcc}
\hline AFB Grading & No. of cases & ADA (U/L)Mean Rank \\
\hline $1+$ & 26 & 19.29 \\
$3+$ & 17 & 26.15 \\
\hline Mann-Whitney U $=150.5$ & $\mathrm{p}=0.08$
\end{tabular}

93.3\% was shown at the Cut-off level of $21 \mathrm{U} / \mathrm{L}$ with least specificity of $93.3 \%$. At the Cut-off point of $30 \mathrm{U} / \mathrm{L}$, the sensitivity was least $81.3 \%$ with highest specificity of $100 \%$.

The Mean Rank Serum ADA level among Pulmonary TB cases with Sputum AFB Grading was shown to be highest 29.97 U/L among 3+ AFB Sputum Graded cases followed by $29.14 \mathrm{U} / \mathrm{L}$ among $2+$ cases and least of $21.6 \mathrm{U} / \mathrm{L}$ among 1+ cases with p value 0.142 (statistically insignificant).

The Mean Rank Serum ADA level was shown highest 26.15 U/L among 3+ Sputum AFB Graded cases than 19.29 U/L among 1+ Sputum AFB Graded cases. The Mean Rank Serum ADA level among these $1+$ and $3+$ cases were not shown to be statistically significant with p value of 0.08 .

\section{DISCUSSION}

We evaluated 75 Nepalese TB subjects in which 49 (65\%) were male and 26 (35\%) were female.
The age of the patients ranged from 15 to 59 years with a mean \pm SD $32.84 \pm 11.44$. The subjects were of two categories: P-TB and EP-TB. Among P-TB cases, 37 (74\%) were male and 13 (26\%) were female of age ranged from $15-59$ yrs. with a mean \pm SD $34.20 \pm 12.37$. For EP-TB cases, 12 (48\%) male and 13 (52\%) female of age ranged from $17-50$ yrs. with a mean \pm SD $30.12 \pm 8.93$ were studied. We also evaluated 75 healthy controls as students and staffs of Dhulikhel Hospital, Nepal of age ranged from 18-47 years with 40 (53\%) of male and 35 (47\%) of female with mean \pm SD $26.13 \pm 5.75$.

There was significant difference in the mean rank of the level of serum ADA among the TB patients to control group. The P-TB had higher mean rank (116.52) followed by EP-TB (99.48) and Normal Control had significantly less mean rank (40.16) with p value 0.001 . We got mean \pm SD of $47.99 \pm 2.22$ among $\mathrm{TB}$ cases with minimum serum ADA level 11.06 U/L and maximum 127.34 U/L whereas among control group mean $\pm \mathrm{SD}$ was $14.98 \pm 4.32$ with minimum serum ADA level $4.67 \mathrm{U} /$ $\mathrm{L}$ and maximum $24.07 \mathrm{U} / \mathrm{L}$.

The serum ADA mean rank in P-TB were higher among $3+$ graded sputum positive patients (29.97) followed by $2+$ (29.14) and $1+$ (21.60) with $p$ $=0.142$. The increase in serum ADA levels among the study group may be due to stimulation of cell mediated immunity. The variation in immune response by the study group might be the reason of data being statistical insignificant.

\begin{tabular}{|c|c|c|c|c|c|}
\hline Research studies & Cut-off point & Specificity & Sensitivity & PPV & NPV \\
\hline Jhamaria JP et al. (1988) & $33 \mathrm{U} / \mathrm{L}$ & $100 \%$ & $98 \%$ & Similar result & $\begin{array}{l}\text { Similar } \\
\text { result }\end{array}$ \\
\hline Kuyucu N et al. (1999) ${ }^{20}$ & $53.76 \mathrm{U} / \mathrm{L}$ & $100 \%$ & $90.7 \%$ & $58.8 \%$ & $100 \%$ \\
\hline Rasooli Nejad M (2003) ${ }^{18}$ & $14.5 \mathrm{U} / \mathrm{L}$ & $80.6 \%$ & $82 \%$ & relatively lower & $\begin{array}{l}\text { relatively } \\
\text { lower }\end{array}$ \\
\hline $\begin{array}{l}\text { Lamsal M et al. }(2007)^{17} \\
\text { Partially resembles }\end{array}$ & $25 \mathrm{U} / \mathrm{L}$ & $81.53 \%$ & $72.42 \%$ & \multicolumn{2}{|c|}{ Partially resembles } \\
\hline Gupta et. Al (2010) & $30 \mathrm{U} / \mathrm{L}$ & $91.25 \%$ & $83.10 \%$ & Similar result & $\begin{array}{l}\text { Similar } \\
\text { result }\end{array}$ \\
\hline Naderi M et al. $(2010)^{16}$ & $12.5 \mathrm{U} / \mathrm{L}$ & $93.3 \%$ & $87 \%$ & $92.5 \%$ & $84.1 \%$ \\
\hline Hassanein K et al. $(2010)^{15}$ & $30 \mathrm{U} / \mathrm{L}$ & $90 \%$ & $87 \%$ & $90 \%$ & $66.5 \%$ \\
\hline Rao KS et al.'s study $(2010)^{14}$ & best supported & $95.35 \%$ & $98.06 \%$ & best supported & $\begin{array}{l}\text { best } \\
\text { supportec }\end{array}$ \\
\hline Stevanovic G et al. (2011) & - & $56 \%$ & $89 \%$ & $80 \%$ & $72 \%$ \\
\hline Bolursaz MR et al. $(2012)^{12}$ & $42 \mathrm{U} / \mathrm{L}$ & higher & higher & - & - \\
\hline Chander A et al. (2012) ${ }^{11}$ & - & $91.25 \%$ & $83.10 \%$ & $94.00 \%$ & $69.52 \%$ \\
\hline AfrasiabianS et al. $(2013)^{10}$ & $14 \mathrm{U} / \mathrm{L}$ & $88.1 \%$ & $92.7 \%$ & $88.4 \%$ & $92.5 \%$ \\
\hline Current studies & $30 \mathrm{U} / \mathrm{L}$ & $100 \%$ & $81.3 \%$ & $81.33 \%$ & $100 \%$ \\
\hline Current studies & $25 \mathrm{U} / \mathrm{L}$ & $100 \%$ & $90.7 \%$ & $90.66 \%$ & $100 \%$ \\
\hline
\end{tabular}




\section{CONCLUSION}

In the rapid progression of science and technology in the field of medicine has overcome many drawbacks of conventional and traditional ways of disease diagnosis, prognosis and monitoring. It used to be time consuming and cumbersome in diagnosis of infectious diseases mainly tuberculosis. Although the study was conducted in narrow limitations, it has provided one small effort to support the easy diagnosis of tuberculosis. Serum ADA can be easily performed as the routine test in diagnosis of tuberculosis which is relatively easy, cheap, specific and sensitive biomarker in establishment of disease diagnosis. The Serum ADA estimation can be used as routine lab investigation for the diagnosis of TB even in basic lab set up. The test procedure does not require any special lab instruments and can be performed on basic lab instruments.

The study was carried out among 75 TB cases and 75 healthy controls. Of 75 healthy control $47 \%$ (35) were female and 53\% (40) were male of age group ranging from $18-47$ years. The mean level of serum ADA was found to be $14.98 \mathrm{U} / \mathrm{L}$ with SD 4.32. We got maximum value of serum $\mathrm{ADA}$ $24.07 \mathrm{U} / \mathrm{L}$ and minimum of $4.67 \mathrm{U} / \mathrm{L}$ among healthy control. The levels of serum ADA among healthy group were within normal limit as per reference range given by reagent company leaflet. The study group of tuberculosis cases was diagnosed by the medical team of NTC along with sputum examination, clinical symptoms, radiological impressions and serological tests like Mantoux test. The TB case group included 35\% (26) female and $65 \%$ (49) male of age ranging from 15 - 59 years. The cases were divided into 2 category; PT (50) and EP-TB (25). The mean serum ADA level in cases was found to be $47.99 \mathrm{U} / \mathrm{L}$ with SD 2.22. The maximum level of serum ADA level was observed 127.34 U/L whereas the minimum level was 11.06 U/L.

The pulmonary TB cases include 26\% (13) female and $74 \%$ (37) males of age ranging from $15-$ 59 years. The mean serum ADA level was found to be 53.03 U/L with SD 2.36. The maximum level of serum ADA was observed 127.34 U/L and minimum of $11.06 \mathrm{U} / \mathrm{L}$. The cases of Pulmonary TB where further categorized depending upon sputum grading: $1+(26), 2+(7)$ and $3+(17)$. The ET-TB cases include 52\% (13) female and 48\% (12) male of age ranging from $17-50$ years. The mean serum ADA level was found to be $37.89 \mathrm{U} / \mathrm{L}$ with SD 1.47. The maximum level of serum ADA was observed $70.10 \mathrm{U} / \mathrm{L}$ and minimum of $15.52 \mathrm{U} / \mathrm{L}$. There was significant difference in mean rank of the level of serum ADA among the TB patients to healthy control. PTB has higher mean rank (116.52) followed by EPTB (99.48) and control (40.16) with $\mathrm{p}=0.001$. There was no significant difference in mean rank of the level of serum ADA among sex wise distribution with $p=0.037$. There was also no significant difference in mean rank of the level of serum ADA among grading wise distribution with $\mathrm{p}=0.142$. The mean rank serum ADA levels of $1+$ sputum AFB grading and 3+ sputum AFB grading were also found to statistically insignificant with $\mathrm{p}=0.08$. Since the highest sensitivity and specificity was shown at cut-off point of $25 \mathrm{U} / \mathrm{L}$, the serum ADA level can be set at $25 \mathrm{U} / \mathrm{L}$ as borderline value according to our study. The present study suggest to use serum ADA estimation as the biochemical marker in the diagnosis of TBhighlighting it as simple, rapid, cheaper and accurate diagnostic test.

\section{REFERENCES}

1. World Health Organization. Diagnostic and Treatment Delay in Tuberculosis. World Health Organization, Regional Office for the Eastern Mediterranean; 2006. p. 21.

2. Storla DG, Yimer S, Bjune GA. A systematic review of delay in the diagnosis and treatment of tuberculosis. BMC Public Health 2008;8:15.

3. Kuyucu N, Karakurt C, Bilaloðlu E, Karacan C, Teziç T. Adenosine deaminase in childhood pulmonary tuberculosis: Diagnostic value in serum. J Trop Pediatr 1999;45:245-7.

4. Jhamaria JP, Jenaw RK, Luh SK, Mathur DK, Parihar HL, Sharma SK. Serum adenosine deaminase (ADA) in differential diagnosis of pulmonary tuberculosis and common non tubercular respiratory diseases. Ind J Tub 1988; 35: 25-7.

5. Piras MA, Gakis C, Budroni M, Andreoni G. Adenosine deaminase activity in pleural effusions: An aid to differential diagnosis. $\mathrm{Br}$ Med J 1978; 2:1751-2.

6. Garcia Zamalloa A, Taboada Gomez J. Diagnostic accuracy of adenosine deaminase and lymphocyte proportion in pleural fluid for 
tuberculous pleurisy in different prevalence scenarios. PLoS One 2012;7:e38729.

7. Sakuraba M, Masuda K, Hebisawa A, Sagara Y, Komatsu H. Pleural effusion adenosine deaminase (ADA) level and occult tuberculous pleurisy. Ann ThoracCardiovascSurg 2009; 15: 2946.

8. Collazos J, España P, Mayo J, Martínez E, Izquierdo $\mathrm{F}$. Sequential evaluation of serum adenosine deaminase in patients treated for tuberculosis. Chest 1998;114: 4325.

9. Stevanovic G, Pelemis $M$, Pavlovic $M$, Lavadinovic L, Dakic Z, Milosevic I, et al. Significance of adenosine deaminase serum concentration in the diagnosis of extra pulmonary tuberculosis. J IMAB 2011;17:130 4.

10. Afrasiabian S, Mohsenpour B, Bagheri KH, Sigari N, Aftabi K. Diagnostic value of serum adenosine deaminase level in pulmonary tuberculosis. 2013; 2012-4.

11. Chander A, Shrestha CD. Diagnostic value of serum adenosine deaminase levels in sputum smear negative pulmonary tuberculosis patients in Nepalese population. Asian Pacific Journal of Tropical Biomedicine. 2012; 2(3):S1896S1899.

12. Bolursaz MR, Khalilzadeh S, Khodayari A, Hakimi S. Adenosine Deaminase Level as an Indicator for Differentiating Between Active Pulmonary Tuberculosis Infection and Other Pulmonary Infections. Journal of Comprehensive Pediatrics. 2012.

13. Stevanovic G, Pelemis M, Pavlovic M, Lavadinovic L, Dakic Z, Milosevic I. Significance of adenosine deaminase serum concentrations in the diagnosis of extrapulmonary tuberculosis. 2011;17(8).

14. Rao KS, Kumar HA, Rudresh BM, Srinivas T, Bhat KH. A Comparative study and evaluation of serum adenosine deaminase activity in the diagnosis of pulmonary tuberculosis. 2010; 2010(2):189-94.

15. Hassanein K, Hosny H, Mohamed R, Abd El Moneim W. Role of adenosine deaminase (ADA) in the diagnosis of pulmonary tuberculosis. Egypt J Bronchol 2010; 4:11 8.

16. Naderi $M$, Hashemi $M$, Mehdizadeh A, Mehrabifar H. Serum adenosine deaminase activity and the total antioxidant capacity of plasma in pulmonary tuberculosis and nontuberculosis pulmonary disease. 2010; 40(5): 701-6.

17. Lamsal M, Gautam N, Bhatta N, Majhi S, Baral N, Bhattacharya SK. Diagnostic utility of adenosine deaminase (ADA) activity in pleural fluid and serum of tuberculous and nontuberculous respiratory disease patients. The Southeast Asian journal of tropical medicine and public health. 2007; 38(2):363-9

18. RasooliNejad $M$. The value of serum adenozinedeaminase in diagnosis of pulmonary tuberculosis. Iran J Infect Dis 2003; 8: 159.

19. Dilmaç A, Uçoluk GO, Uðurman F, Gözü A, Akkalyoncu B, Eryilmaz T, et al. The diagnostic value of adenosine deaminase activity in sputum in pulmonary tuberculosis. Respir Med 2002; 96: 6324.

20. Kuyucu N, Karakurt C, Bilaloglu E, Karacan C, Tezic T. Adenosine deaminase in childhood pulmonary tuberculosis:diagnostic value in serum. J Trop Pediatr 1999; 45: 245-247. 